\title{
Transitioning Australian Disability Enterprises to open employment community hubs using the Australian legislative framework
}

\author{
Peter Smith $^{\mathrm{a}, \mathrm{b}, *}$, Peter Rhodes ${ }^{\mathrm{a}, \mathrm{b}}$, Lauren Pavlidis ${ }^{\mathrm{a}, \mathrm{b}}$, June Alexander $^{\mathrm{a}, \mathrm{c}}$ and Keith R. McVilly \\ ${ }^{a}$ Centre for Disability Employment Research and Practice, Melbourne, VIC, Australia \\ ${ }^{\mathrm{b}}$ School of Social and Political Sciences, The University of Melbourne, VIC, Australia \\ ${ }^{\mathrm{c}}$ Flinders University, Adelaide, SA, Australia
}

Revised/Accepted November 2018

\begin{abstract}
.
BACKGROUND: The transition of sheltered workshops or Australian Disability Enterprises (ADE) as they are known in Australia, to open employment settings unlike the USA lacks the legislative driver to encourage providers to move towards the promotion of integrated employment in the community. As a result, we have witnessed a move to rebadge ADE's as social enterprises in order to change public perceptions, without changes in wage outcomes or pathways to real work in the community. ADE's in Australia present as something of a challenge for government in trying to balance the competing provider agenda, against its obligations to people with a disability underpinned by the Disability Services Act (1986), the United Nations Convention on the Rights of People with a Disability and the establishment of the National Disability Insurance Scheme (NDIS).

OBJECTIVE: This paper will examine the policy drivers for change and findings from work undertaken by the Centre for Disability Employment Research and Practice (CDERP) to promote provider transformation to integrated employment settings and the issues experienced in provider transformation within these policy settings.

CONCLUSION: Education, ongoing support for employment staff and families, along with community partnerships are seen as ingredients for creating provider transformation and meaningful employment outcomes.
\end{abstract}

Keywords: Policy, NDIS, UNCRPD, top down, bottom up, customised employment, transformation, families, safe harbour, security, employers, mentoring, training, participants, value stream mapping

\section{Introduction - disability employment policy settings}

\subsection{Policy Drivers 1948-Present}

Disability employment services in Australia were primarily established after World War One when

\footnotetext{
*Address for correspondence: Dr Peter Smith, Centre for Disability Employment Research and Practice, L24, 570 Bourke St., Melbourne, Australia. Tel.: +61 427 813840; E-mail: peter. smith@cderp.com.au.
}

the Commonwealth Government established the Repatriation Commission to provide vocational training to ex-servicemen with disabilities.

The medical model of rehabilitation continued as the dominant model until 1941 when the Commonwealth Government amended the Invalid and Old Age Pensions Act (1908) to allow the government to offer vocational training to invalid pensioners, then known as The Vocational Training and Invalid Pensioners scheme and administered by the Department of Social Security. 
In 1948, an amendment to the Social Security Act, allowed the department to offer an expanded range of services that led to the establishment of a scheme known as the Commonwealth Rehabilitation Service (CRS), which formalised the dual role of the Commonwealth government in rehabilitation and disability employment. In a sense, this duality of purpose was a result of pressure from the medical profession to utilise a medical model of rehabilitation, with many centres set up in hospitals, something that the then Commonwealth government was unopposed to.

The Commonwealth Rehabilitation Service program was based on the Royal Australian Air Force (RAAF) model of rehabilitation that focused on convalescence and vocational retraining. The genesis of the RAAF model during the Second World War was the RAAF need to focus on effective and quick rehabilitation to return scarce pilots to active duty (O'Halloran, 2002). The combining of rehabilitation with vocational training served to highlight employment as one of the aims of government policy in this area, something that remains a focus of government rehabilitation and disability policy to this day.

Vocational training became a feature of the Commonwealth Rehabilitation Service from 1948 when with the agreement of the Australian Council of Trade Unions (ACTU), the Commonwealth Rehabilitation Service established what was known as the "work therapy scheme" with the use of the term therapy a method of relieving employers of any requirement to pay wages for work experience (Tipping, 1992).

In 1974, the Woodhouse and Meares Inquiry into Compensation and Rehabilitation recommended that the Commonwealth Rehabilitation Service establish smaller regional centres that removed the focus on medical rehabilitation and large capital city-based centres. These new centres were closely aligned with community-based resources, such as education and community health care and potentially served to fill a need in regional and country areas for services to returning service personnel.

The broadening of eligibility in the 1970's allowed any Australian resident with a disability whose disability prevented access to work or independent living (APH, 1998) to access CRS services. The Australian Commonwealth Government, using the Commonwealth Rehabilitation Service (CRS) facilitated work trials through the establishment of seven work preparation centres, that saw school leavers with mild intellectual disability given intensive job skills and social skills training. Over a period of twelve to eighteen months, participants received training in these skill sets and were able to obtain employment in the open labour market in manufacturing that was at that time the dominant employer group. These programs ran using the supported employment model based on evidence coming out of the USA (Ward, Parmenter, Miller, \& Debenham, 1977). In a sense, these centres were precursors to the Transition to Work programs that exist in most states and territories in Australia.

In tandem with the rehabilitation model, sheltered workshops or Australian Disability Enterprises (ADE) as they are known today, began being established by family, voluntary and private groups to employ people with a disability who could not find work in the open employment market. At that time, options for people with significant disabilities were limited to attending congregate day activities or finding your path in the community, which mostly meant sitting at home (Symonds \& Luecking, 2013). Sheltered workshops operated outside of general employment legislation with employees receiving minimal financial reward for their efforts, although the Commonwealth government at that time offered workshop providers a training fee of $\$ 500$ for each client moved into open employment (Parmenter, 1980). This was despite many being established on the premise of teaching farm skills to people with intellectual and developmental disability. In this sense, the participants were viewed as unemployable in the open market, which seemed to reinforce the long-held view of a low expectation of any real capacity to work.

Sheltered workshops at that time operated mainly as day activity programs that focused on daily living skills, social and recreational activities. It could be argued that they also functioned as custodial settings that provided respite to carers and family. In the nineteen seventies, evidence began to accumulate that with appropriate supports people with disabilities could develop skills that could be transferred to open employment. Marc Gold's work in the early seventies and his "Try Another Way" process demonstrated viable training pathways, which along with the evolving normalisation movement started to create pressure on sheltered workshops to evolve into open employment opportunities.

Current Disability Employment policy drivers have their origins in The New Directions (1985) report which preceded the introduction of the Disability Services Act (1986) by the Commonwealth government that established the rights of people with a disability to full and open employment and laid the scene for the integration of employment, training, reha- 
bilitation and accommodation as pre-cursors to the promotion of self-determination amongst people with a disability (Ford, 1998).

Before the introduction of the Disability Services Act (1986), some disability employment projects were established as demonstration projects to establish whether people with a disability could achieve open employment outcomes. An example of these types of programs was the Epilepsy Association of South Australia's Training and Placement Service (TAPS) that was funded by the Commonwealth Department of Employment and Industrial Relations (DEIR). This program included training over ten weeks fulltime that covered a variety of personal, leisure and work skills culminating in work experience and potential employment with follow up supports (Parmenter, 1986).

In line with the push towards deinstitutionalisation as a result of the normalisation movement based on the works of Nirje and Bank-Mikkelson from Scandinavia in the 60's and later, Wolfensburger in the USA in the 70's, the Disability Services Act (1986) became the overarching framework for the delivery of employment services nationally, which led to the establishment of the Disability Employment Network, whose role was to promote and support open employment for people with a disability. Social justice principles largely underpinned these services and administered by the then Department of Family \& Community Services (FACS). An outcome of the 1992 Commonwealth-State Disability Agreement saw state and territory governments retained responsibility for all other disability services such as day and residential services, while the Commonwealth Government took responsibility for employment.

Following from the Disability Services Act (1986) a set of Disability Service Standards were introduced in 1992 that set standards for access, compliance, policy and procedure amongst other things that service providers were required to meet to secure funding (Symonds \& Luecking, 2013).

Ford (1998) noted that the Disability Services Act (1986) at that time encouraged sheltered workshops to support those clients with the capacity to pursue open employment to be supported to do so by providing training, work skills and transportation training. At the same time, sheltered workshops were encouraged to become quality services that reflected the intent of the Disability Services Act (1986). Interestingly, these three capacity building items reflect the intent and purpose of the current National Disability Insurance Scheme (NDIS) transition to work funding known as the School Leaver Employment Support (SLES) funding.

Transition to open employment from sheltered workshops was hindered or unlikely in part due to limited technical expertise in areas of employment interest and training possessed by support staff and the limited variety of low-paying work and low-skilled experiences provided within sheltered workshops that tended to operate within the packaging and assembly industry (Smith \& McVilly, 2016). This mostly continues today, in part due to a lack of investment in equipment and staff that would allow sheltered workshops to compete with lower cost manufacturers and low-wage cost overseas competitors. What further complicates the present situation for sheltered workshops or Australian Disability Enterprises (ADE's) is that they predominately function as not for profits operating for a social benefit and are heavily dependent on government support and charitable donations (Smith, McVilly, McGillivray, \& Chan, 2018).

Following a review in 2008 of employment services, the previous DEN program and Vocational Rehabilitation Service (VRS) were replaced by a single program; Disability Employment Service (DES) with DEN now renamed Employment Support Service (ESS), and VRS renamed Disability Management Services (DMS). A mixture of private providers delivered DMS services, and the Commonwealth owned CRS until 2015, when under the policy direction of the Commonwealth Liberal Government, CRS ceased to exist, and all DMS services that it had delivered were moved to private providers through a tender process.

\section{United Nations Convention on the Rights of Persons with Disabilities (2006) (UNCRPD)}

To underscore the significance of the convention, it is essential to highlight the following parts of the document; Article One (1) of the United Nations Convention on the Rights of Persons with Disabilities (UNCRPD) (2006) states

"The purpose of the present Convention is to promote, protect and ensure the full and equal enjoyment of all human rights and fundamental freedoms by all persons with disabilities, and to promote respect for their inherent dignity. Persons with disabilities include those who have longterm physical, mental, intellectual or sensory impairments which in interaction with various 
barriers may hinder their full and effective participation in society on an equal basis with others."

This positions the UNCRPD as a human rights agenda.

Section twenty-seven highlights the convention signatories' obligations regarding work and employment. It lists eleven steps that signatories should take to safeguard and promote opportunities for people with a disability to work. These steps are:

(a) Prohibit discrimination on the basis of disability with regard to all matters concerning all forms of employment, including conditions of recruitment, hiring and employment, continuance of employment, career advancement and safe and healthy working conditions;

(b) Protect the rights of persons with disabilities, on an equal basis with others, to just and favourable conditions of work, including equal opportunities and equal remuneration for work of equal value, safe and healthy working conditions, including protection from harassment, and the redress of grievances;

(c) Ensure that persons with disabilities are able to exercise their labour and trade union rights on an equal basis with others;

(d) Enable persons with disabilities to have effective access to general technical and vocational guidance programmes, placement services and vocational and continuing training:

(e) Promote employment opportunities and career advancement for persons with disabilities in the labour market, as well as assistance in finding, obtaining, maintaining and returning to employment;

(f) Promote opportunities for self-employment, entrepreneurship, the development of cooperatives and starting one's own business;

(g) Employ persons with disabilities in the public sector;

(h) Promote the employment of persons with disabilities in the private sector through appropriate policies and measures, which may include affirmative action programmes, incentives and other measures;

(i) Ensure that reasonable accommodation is provided to persons with disabilities in the workplace;

(j) Promote the acquisition by persons with disabilities of work experience in the open labour market; (k) Promote vocational and professional rehabilitation, job retention and return-to-work programmes for persons with disabilities. (UNCRPD, 2006).

The Australian Commonwealth Government ratified the UNCRPD in July 2008 obligating the government to improve the lives of people with a disability under with the convention. In February 2011, the Council of Australian Governments (COAG) endorsed a new National Disability Strategy 2010-2020 incorporating the principles of the UNCRPD. Central to this document is the policy direction to provide increased access to employment opportunities for people with a disability. It is noted that employment is the pathway used by most Australians to enjoy long-term economic security and well-being.

\subsection{The National Disability Insurance Scheme}

In July 2013, the Australian government implemented the rollout of the National Disability Insurance Scheme (NDIS), a new system that would change the way the Australian community would support persons with disabilities. It intends to shift disability service funding from a welfare model to an early intervention focused insurance model.

The National Disability Insurance Scheme is an Australia-wide scheme designed to support people with permanent and significant disability. Persons with disabilities have the right to decide their own best interests and to have choice and control over their lives and the reasonable and necessary supports they require to enhance their social and economic independence.

Under the new insurance model, enablement will remain a central theme, which aims to shift individual focus away from "survival in a community filled with barriers" to a vision of a future life with no barriers and a journey built around a community which values full inclusion. This new system, which is underpinned by the legislative obligations provided by the United Nations Convention on the Rights for Persons with Disabilities (UNCRPD) and the NDIS Act 2013, will be controlled for the first time by a federally funded body, the National Disability Insurance Agency (NDIA), whose role is to oversee both the continuing rollout of the Scheme around the nation and the future administrative sustainability of the Scheme. 
Under both the UNCRPD and the NDIS Act 2013, the Australian government is further committed to better outcomes with employment and career opportunities for persons with disabilities. The following paragraphs will highlight critical extracts from both, the UNCRPD and the NDIS Act 2013, dedicated to its obligations and policy direction for work and employment. Statements made by both documents should form the reflective framework for any new policy directions undertaken in disability employment in Australia.

As part of the new legislative obligations, the NDIS Act 2013, the NDIS has a vital role to play in improving employment outcomes for persons with disabilities through enhanced economic participation.

The following is an extract of key parts of the Act.

\subsection{Chapter 1, Section 3.}

\subsubsection{Objects of Act}

The objects of the Act are to:

(a) in conjunction with other laws, give effect to Australia's obligations under the Convention on the Rights of Persons with Disabilities (UNCRPD) done at New York on 13 December 2006 ([2008] ATS 12);

(b) support the independence and social and economic participation of people with disability and ...

(e) enable people with disability to exercise choice and control in the pursuit of their goals and the planning and delivery of their supports and

(h) raise community awareness of the issues that affect the social and economic participation of people with disability, and facilitate greater community inclusion of people with disability

For the first time, persons with disabilities in Australia will have protective legislation from local and international courts, which support respect, independence and full inclusion in society. From a service provision perspective, providers and consumers of services have significant legislative imperatives to deliver appropriate person-centred employment services. The legislation, however, does little to determine how providers deliver services and while service provision must meet compliance requirements, it does little to enable the provision of services that facilitate true client choice and control.

\section{Practice settings}

This research has been undertaken within the settings of an Australian Disability Enterprise (ADE), and a Disability Service Provider seeking to deliver employment services within what is traditionally a lifestyle support service using grant and philanthropic funding. Both providers benefited from grant funding that was secured to undertake additional work to develop an understanding of what an appropriate Customised Employment training curriculum would look like. The outcome of that project is a separate piece of research and not the subject of this research paper. The provider participants are located in geographically different areas. It should be noted that one other service provider participated in the training with the view towards understanding the role of the Discovery process.

Both providers intend to develop employment services underpinned by customised employment methodology, as part of a larger transformation process driven in part as a response to the establishment of the National Disability Insurance Scheme (NDIS). The NDIS brings with it changing client expectations that real client choice and control underpinned by individualised funding can be achieved under the new paradigm.

\subsection{Lessons from the field}

This section will examine practice outcomes and observations of the perspective of the provider, provider staff and the participant and family. Given that change involves altering the relationship between all people involved, there is some overlap between the three participant groups. As such these observations will be blended as necessary. Field observations will be contrasted against known evidence.

\subsubsection{It starts at the top and the bottom- everyone is welcome to have a say}

Current work undertaken CDERP takes a top down and bottom up approach to provider change. In effect, this is about ensuring that everyone understands what is going to happen and its impact on them. Most recent projects have involved detailed meetings with senior management and staff to inform and educate them on the processes, particularly the impact of implementing Customised Employment as an organisation-wide approach to employment. The importance of this approach is widely accepted within employment lit- 
erature (Mills, Pollack, Rogan, \& Sasnett, 2017) and within organisations that have undertaken transformation processes. It was evident within the larger project that informs this paper that senior management must be involved in the transformation process to gain any internal support.

We found different experiences within the three providers that could be described as full buy-in, partial buy-in and management delegation. In the case of full buy-in while the transformation process presents with challenges, the hands-on support from management has illustrated to staff that their work is valued and that any barriers will be worked through. At the opposite end of this was management delegation of the idea which resulted in limited support for staff that had been trained and indeed the process of embedding Customised Employment was viewed as something to be done after all the staff regular duties had been completed. This was also clouded in the issue around who would pay for the staff time allotted to undertaking employment work with clients.

Within the provider organisations, just as important as management buy-in, is the necessity of staff buy-in . In order to embrace the process of changing to what is effectively a Work First approach, it is essential for all staff involved to be able to express themselves openly and without fear of retribution. It is not uncommon during change processes for staff to be selected for a project without any real understanding of what they are involved in and without any capacity to question the process.

In order to address the possibility of creating confusion, it was seen as critical to holding meetings with the selected staff to allow them to ask questions and voice any concerns that they had with both management and CDERP staff. This is best done before any training of staff takes place and before the change process is introduced to the broader provider community.

Once you have a roadmap for the organisation and staff, it is vitally important to inform participants and families. We have found that holding community forums for the participants, families and community members such as schools, teachers and careers advisors is an essential ingredient. For participants who have a long history with the organisation, there can be a palpable shock when significant change is going to take place. In one recent session, it became apparent when quietly listening to the conversations taking place in the audience that the initial impression was that the change would result in the service participants and families were no longer able to be supported by the organisation. This highlights the importance of holding open forums where everyone can ask questions and have their fears allayed. Similar to this, it has become apparent that while service providers exist in their communities and have done so for a significant amount of time, the practical reality is that unless you are a service user, there is a genuine possibility that what you do is mostly a mystery to the community at large.

There is a growing evidence base for the use of community conversations as a tool to engage both participants and the wider community (Flippo \& Butterworth, 2018). In their review of the Partnerships in Employment National Transition to Employment Systems Change Project, Flippo and Butterworth (2018) stated;

"Community conversations are a non-traditional approach for systems change and shift the power dynamic from individuals and institutions that tell us what to do and have the authority to do so, to one that gives power to the community as those responsible for turning the policy into practice. Community conversations reinforce the concept that participants are drivers for change." (p.8)

This process has been used successfully in the Tennessee Works Partnership which formed part of the National Partnerships in Employment program which was evaluated by Flippo and Butterworth (2018). The outcomes from our community conversations and program to educate families and participants support the growing evidence for the effectiveness of community conversations as an intervention for change.

\subsubsection{It is more than just training - you have to bring out your dead!}

Training staff in a new employment methodology and expecting it to flourish can be a recipe for failure. The training process will challenge staff beliefs about their capacity and that of the people they support. This is a process of culture change, of challenging the old norms and values. Experience has shown us that very quickly staff that don't believe in the capacity and desire for everyone to pursue meaningful employment will leave your organisation. This is a challenge to be managed by senior staff, but it is an opportunity for renewal. Debbie Ball from Easterseals, California refers to it as a process of getting the right people on the bus and getting the wrong people off the bus (Ball, personal communication, 2017). It has been our experience to date as well. People and the commu- 
nity will often talk about everyone with a disability has the right to pursue meaningful employment, but when it comes to "the rubber meeting the road" this is often met with comments such as, "oh you mean those people."

Coupled with getting the right people on the bus is the removal of old practice and policies that become barriers to change. Too often old policies and ways of doing things remain the elephant in the room. It should be obvious, but who is paying attention to them? This is where ongoing mentoring on a weekly basis is a crucial ingredient once the training has been completed. Training completion is a bit of a misnomer, in that the learning and training never stop. We have found that supporting organisational change and staff weekly for the first year is an active ingredient in ensuring that progress is made. Often staff are reluctant to discuss issues with management is partly due to the belief that they already understand what the barriers are. Weekly mentoring gives us the opportunity to receive feedback and when necessary develop an intervention. This is supported by monthly meetings with management and staff to discuss progress and plans.

One method that we have found very useful in aiding in the elimination of old policy and practice is the use of Value Stream Mapping (VSM). VSM has its origins in manufacturing where it is used to highlight waste and focus resources on practices that add value to the customer service or product. In essence, it is about improving efficiency and was introduced to CDERP by Sara Murphy at Worklink, San Francisco (Murphy, personal communication, 2017). Worklink have been using VSM as part of their organisational change practices with great success. In our work with provider transformation, we have found that the use of Present State Mapping (PSM) is a highly useful tool for identifying what happens to organisation clients. Using PSM, we work with management and staff to chart a week in the life of a client who enters the service provider. This process always throws up unexpected barriers and duplication, along with processes that everyone is undertaking, but no one can understand why. This process highlights the disconnects, the gaps in service delivery and the system redundancies that stand in the way of efficient service delivery (Martin \& Osterling, 2013). Using this process, we can eliminate barriers that prevent staff from working to their potential and improve client participation. One outcome of this process has been clients use the outcomes to revise their mission statement and values.

\subsubsection{Holding hands with staff, participants and families}

Change within any organisation brings with it a certain level of anxiety. This is particularly so for participants and family. Being a part of a stable organisation brings with it a level of security and safety by the trusting relationships that have been built up with staff and other families. Change throws up the possibility of this being dissipated and the real possibility that we may not have the services that we want. For staff, there is a different type of anxiety, no less real that surrounds perceptions of job security and what if I get this wrong questions. There is a benefit to be obtained by staff undertaking the Discovery process on themselves. In our work, we teach the Griffin-Hammis developed Discovering Personal Genius (DPG) which has in our view a better-developed job development framework through the use of Vocational Themes, in particular, the Lists of Twenty. This process widens the job search and is useful for staff who have undertaken it themselves to conduct a handful of informational interviews in businesses that relate to their themes.

Education and information is king in this situation. For families and participants, we have found that you can never give them enough information. The CEO of one of the participant organisations made a point of having an open-door policy that allowed everyone; staff, participants and families to come through his door and ask questions. Allied with the use of community conversations (Dutta, Kundu, Johnson, Chan, Trainor, Blake \& Christy, 2016), this process very quickly allayed fears and developed interest amongst potential participants and families.

These first adopters form the nexus of the change process which evidence and experience highlight that starting small with those that are enthusiastic creates a wave of interest once other people see the success (Rogan \& Strully, 2007). The first families are supported with the same information that staff have been trained in, along with an abridged version of the Customised Employment training. In reality, our experience has shown that training families in the use of Self-Guided Discovery creates a robust understanding of the processes that their child will participate in and aides in the development of trust in the staff and organisation. This creates the conditions of safety that many families are fearful of losing in any change process. This process is similar to the Family Employment Awareness Training (FEAT) that was trialled in Kansas. FEAT is noted as a family-focused employment intervention designed 
to increase employment expectations and knowledge amongst families of participants seeking employment (Gross, Francis \& Pijim, 2014).

There are many benefits in developing this type of relationship, particularly when you consider one of the primary outcomes of any employment process should be heightened levels of self-determination and self-advocacy for the participants (Wehman, Taylor, Brooke, Avellone, Whittenburg, Ham, Brooke \& Carr, 2018). With the client, an active partner, an informed participant they along with their employment support staff member go on the learning journey together. They make mistakes together, and they share in the successes together. Relationships have been shown to be one of the primary factors influencing meaningful employment outcomes for people with a disability (Smith, 2018) and this process creates those relationships anew. Our experience to date has shown that parents of participants who successfully achieve meaningful employment outcomes become the organisations greatest advocates and supporters of the employment initiative.

\subsubsection{Employers - we are not the enemy!}

It is not uncommon for employment staff to view employers as the enemy with a dislike of employing people with a disability. This view can also be shared by people with a disability, primarily based on their employment and job search experiences (Smith, 2018). Despite decades of disability awareness training, employment rates for people with a disability remain stubbornly low; indeed there's an argument to support the proposition that they have flatlined for decades (Australian Commonwealth Government, 2016). It raises the question as to whether the approach adopted by traditional employment service providers is still fit for service.

Customised Employment utilises a different approach through the use of informational interviews to engage with employers on a more personal level. Informational interviews are can be likened to a conversation with a purpose. That purpose is to discover information about the business such as what happens here, what sort of skills do staff need to get into this industry and general information. It is not about looking for a job, but about building a relationship (Griffin, Hammis \& Geary, 2007). This is one area where we find newly trained staff will fail, not because they do not know what to do, but in their zeal to find success, anxiety gets the better of them, and they go straight for the job. All too often this results in a negative response, which has the down- side of halting a relationship before it gets going and also diminishing the consultant's emerging confidence (Smith, 2018).

It is this part of the employment process where we have found that ongoing support and retraining is often needed, which highlights an area of skill development that needs a greater focus. It is our view that consultants would benefit from having a deeper understanding of why employers, particularly small and medium-sized businesses (SME) hire. While there is significant evidence on the hiring practices of large business, the SME sector remains under-researched.

\section{Discussion}

The implementation of the NDIS in Australia is a large-scale movement to participant choice and control using an individualised funding model based on insurance principles. While the NDIS is a seismic shift in funding for participants and providers, it does not provide a legislative imperative for providers to change their structures and practices. This is left to market forces and the idea that the paradigm change will foster innovation in provider practices. This has led to a fragmented market and confusion amongst families and participants who are attempting to grapple with what could be described as mixed messages and inconsistent planning outcomes. The previous system was based on welfare and paternalism and an attitude that we know best from government and providers towards service users and families. Much of this attitude still exists among providers; however, we are slowing seeing providers who take the attitude that we are community partners moving away from paternalism towards real active client and community partnerships. These partnerships are underpinned by information and education that support client selfdetermination and choice and control.

There is an overwhelming need for providers to invest in their future through developing staff and setting in place the ideal conditions for the delivery, along with investing in connecting with and educating not just clients but the broader community (Wehman et al., 2018). This presents with it the opportunity to develop open employment pathways through the creation of social capital within the community and families of participants.

Our practice experience to date is consistent with overseas experiences. It suggests that in the absence of legislative imperatives, provider transformation to 
true client choice and control will be piecemeal and not produce the employment dividends so significant to individuals in society, a society that defines individuals by their valued roles in the employment setting.

The use of community conversations is educating and informing participants and families is one essential ingredient in improving expectations about employment. Supported by organisational transformation based on investing in the organisation and staff and supporting them long term when combined with empowered participants and families can be a powerful force for change. Participants, families, providers and the community combined and supported by external expertise (Mills et al., 2017) and evidence-based practices can deliver effect change in the absence of policy imperatives.

\section{Conflict of interest}

None to report.

\section{References}

Australian Government. (1998). Bills Digest No. 172 1997-98 Commonwealth Rehabilitation Service Reform Bill 1998. Retrieved 1/12/2017 from https://www.aph.gov.au/Parliamen tary_Business/Bills_Legislation/bd/BD9798/98bd172

Australian Commonwealth Government. (2016). Labour market assistance outcomes (various publications). Retrieved from https://www.employment.gov.au/labour-market-assistanceoutcomes-reports

Dutta, A., Kundu, M. M., Johnson, E., Chan, F., Trainor, A., Blake, R., \& Christy, R. (2016) Community conversations: Engaging stakeholders to improve employment-related transition services for youth with emotional and behavioural disabilities. Journal of Vocational Rehabilitation, 45, 43-51.

Flippo, K., \& Butterworth, J. (2018). Community conversations and transition systems change. Journal of Vocational Rehabilitation, 29(1), 7-11.

Ford, J. (1998). Employment opportunities for people with disabilities: The view from Australia. Journal of Vocational Rehabilitation, 10, 71-81.

Griffin, C., Hammis, D., \& Geary, T. (2007). The job developer's handbook: Practical tactics for customized employment. Baltimore, MD: Paul H. Brookes Publishing Co.
Gross, J., Francis, G., \& Pijim, M. A. (2015). Family Employment Awareness Training (FEAT) in Kansas: Description of a family focused intervention and the rationale supporting it. Journal of Vocational Rehabilitation, 43, 217-228.

O'Halloran, D. (2002). An historical overview of Australia's largest and oldest provider of vocational rehabilitation - CRS Australia. Work, 19, 211-218.

Martin, K., \& Osterling, M. (2013) Value stream mapping: How to visualise work and align leadership for organisational transformation. New York, NY: McGraw Hill Education.

Mills, 1., Pollack, R., Rogan, P., \& Sasnett, G. (2017). Provider transformation manual. Washington, DC: U.S. Department of Labor, Office of Disability Employment Policy.

Parmenter, T. R. (1980). Vocational training for independent living. New York, NY: World Rehabilitation Fund.

Parmenter T. R. (1986). Bridges from school to working life for handicapped youth: The view from Australia. New York, NY: World Rehabilitation Fund.

Rogan, P., \& Strully, J. L. (2007). Moving from facility-based day services to integrated employment and community supports. In P. M. Walker \& P. Rogan (Eds.), Make the day matter! Promoting typical lifestyles for adults with significant disabilities. Baltimore, MD: Paul H. Brookes Publishing Co.

Smith, P. J. (2018). A systems analysis of factors that lead to the successful employment of people with a disability. Doctoral Thesis, University of Sydney.

Smith, P. J., \& McVilly, K. R. (2016). Social enterprise: An ethical and commercially responsible way for supporting the social and economic inclusion of people with a disability. Melbourne, Victoria: Yooralla.

Smith, P., McVilly, K., McGillivray, J., \& Chan, J. (2018). Developing open employment outcomes for people with an intellectual disability utilising a social enterprise framework. Journal of Vocational Rehabilitation, 43, 59-77.

Symonds, P., \& Luecking, R. G. (2013). Open employment in Australia. Journal of Vocational Rehabilitation, 38(3), 215222.

The United Nations. (2006). Convention on the Rights of Persons with Disabilities. Treaty Series, 2515, 3.

Tipping J. (1992). Back on their feet: A history of the Commonwealth Rehabilitation Service, 1941-1991. Canberra, ACT: AGPS

Ward, J., Parmenter, T. R., Miller, V., \& Debenham, D. (1977). Vocational preparation for the mildly retarded: An investigation into employment patterns and related factors. National Rehabilitation Digest, 3, 29-45.

Wehman, P., Taylor, J., Brooke, V., Avellone, L., Whittenburg, H., Ham, W., Brooke, A., \& Carr, S. (2018). Toward competitive employment for persons with intellectual and developmental disabilities: What progress have we made and where do we need to go. Research and Practice for Persons with Severe Disabilities, 1-14. 